\title{
Annulus-edge-papillary stitch to repair P2 of the mitral valve posterior leaflet
}

\author{
Samer Kassem, MD, ${ }^{\mathrm{a}}$ and Majed Othman, MD, ${ }^{\mathrm{b}}$ Milan, Italy, and Damascus, Syria
}

It has been accepted that patients undergoing mitral valve (MV) repair have fewer valve-related complications than patients undergoing MV replacement. ${ }^{1}$ After numerous studies, MV repair has therefore become the preferred treatment for degenerative MV disease. ${ }^{2}$ Degenerative mitral regurgitation is one of the most frequent cardiovascular disorders requiring surgical treatment. ${ }^{3}$ Because degenerative MV regurgitation is often due to the prolapse of the middle scallop of the mitral posterior leaflet (PL) (P2), ${ }^{4}$ many corrective techniques have been developed and used with excellent success. We describe a new technique to repair MV insufficiency caused by a prolapsed high middle scallop of the PL (P2). The annulus-edgepapillary (AEP) muscle stitch is a new artificial chord between the papillary muscle and the corresponding point of the posterior mitral annulus anchoring the edge of the prolapsing $\mathrm{P} 2$.

\section{SURGICAL TECHNIQUE}

Transesophageal echocardiography is performed, and cardiopulmonary bypass is established. Antegrade and retrograde cold-blood cardioplegia, $\mathrm{CO}_{2}$ insufflation of the operative field, and moderate hypothermia $\left(32^{\circ} \mathrm{C}\right)$ are routinely used. The valve is inspected, and after confirmation of the prolapsing P2, a pair of 5-0 polytetrafluoroethylene (Gore-Tex; WL Gore \& Associates, Inc, Newark, Del) sutures are passed through a pledget and the posterior MV annulus from the atrial to the ventricular side at the site corresponding to the tip of the prolapsing $\mathrm{P} 2$. A nonsliding knot is then tied on the ventricular side (Figure 1, A). The 2 arms of the sutures are passed through the thickened P2 free edge from the ventricular to the atrial side and tightly knotted on the atrial surface (Figure 1, $A$ ). Thereafter, the 2 needles are passed through the tip of the appropriate papillary muscle with a backhanded technique and then through an expanded polytetrafluoroethylene pledget without tying (Figure 1, B,

From the Department of Cardiovascular Surgery, ${ }^{\mathrm{a}}$ Centro Cardiologico Monzino IRCCS, Milan, Italy; and Department of Cardiac Surgery, ${ }^{\mathrm{b}} \mathrm{Al}$ Bassel Heart Institute, Damascus, Syria.

Disclosures: Authors have nothing to disclose with regard to commercial support.

Received for publication Dec 11, 2010; accepted for publication Feb 9, 2011; available ahead of print Mach 21, 2011.

Address for reprints: Samer Kassem, MD, Centro Cardiologico Monzino, Via Parea 4, 20138 Milan, Italy (E-mail: skassem@ccfm.it).

J Thorac Cardiovasc Surg 2011;141:e44-7

$0022-5223 / \$ 36.00$

Copyright (c) 2011 by The American Association for Thoracic Surgery

doi: $10.1016 /$ j.jtcvs.2011.02.016
$C$ ). Thus, the new chord has an obtuse angle formed by a vertex (the P2 edge ) and 2 rays: the edge-papillary (E-P suture) and edge-posterior annulus (E-A suture). By using the nonprolapsed anterior leaflet as a guide, the length of the E-P component is determined, taking into consideration that it should be shorter than the non-prolapsing chord to bring down the excessive portion of $\mathrm{P} 2$ into the ventricular cavity. A metal clip is placed across the 2 arms of the E-P suture ahead of the expanded polytetrafluoroethylene pledget. The valve is tested by injecting cold saline into the ventricular cavity, and the valvular competence is determined by the length of the E-P component. The 2 arms are then tied tightly against the clip, which is removed and cut (Figure $1, D$ ). The annuloplasty ring is sized according to the height of the well-stretched anterior leaflet, and a slightly oversized ring is inserted into the mitral annulus with interrupted horizontal mattress sutures of 2-0 Polydek, being careful to keep free the pledget of the untied atrial E-P suture (annular chordal anchor) behind the ring's midposterior portion (Figure 1,E). Once the ring is in its definitive position, the valve is again tested by injecting cold saline with considerable pressure (Figure 1,E). The height of the P2 is controlled by the E-A component's length, so the untied atrial suture behind the ring is carefully pulled to decrease the height of $\mathrm{P} 2$ (Figure 2, A), allowing the A2 of the anterior leaflet to occupy its space on the radial direction of the valvular area until the MV regains its smile-shape and the first slight insufficiency appears, while both the left ventricle and leaflets are distended under the filling pressure (Figure 2, B). A metal clip is engaged across the 2 arms behind the mid-posterior portion of the ring. The 2 arms are then tied tightly against the clip and cut. The clip is removed.

If the $\mathrm{P} 2$ is high and wide with a notable shape of a square, rectangle, or trapezoid, more than 1 AEP stitch should be made with the same technique (Figure 2, C). In cases with a high risk of systolic anterior motion, for example, a small left ventricular cavity or redundant anterior leaflet, and before repairing the MV with the AEP stitch, the P2 can be remodeled by a small triangular-shaped resection with the apex toward the annulus (Figure 2, $D$ and $E$ ).

Since August 2010, we have applied the AEP stitch technique in 5 patients with severe MV regurgitation caused by isolated prolapse of a high $\mathrm{P} 2$ with excellent results. After the MV repair, transthoracic echocardiography confirmed a successful repair free of systolic anterior motion on short-term follow-up. 


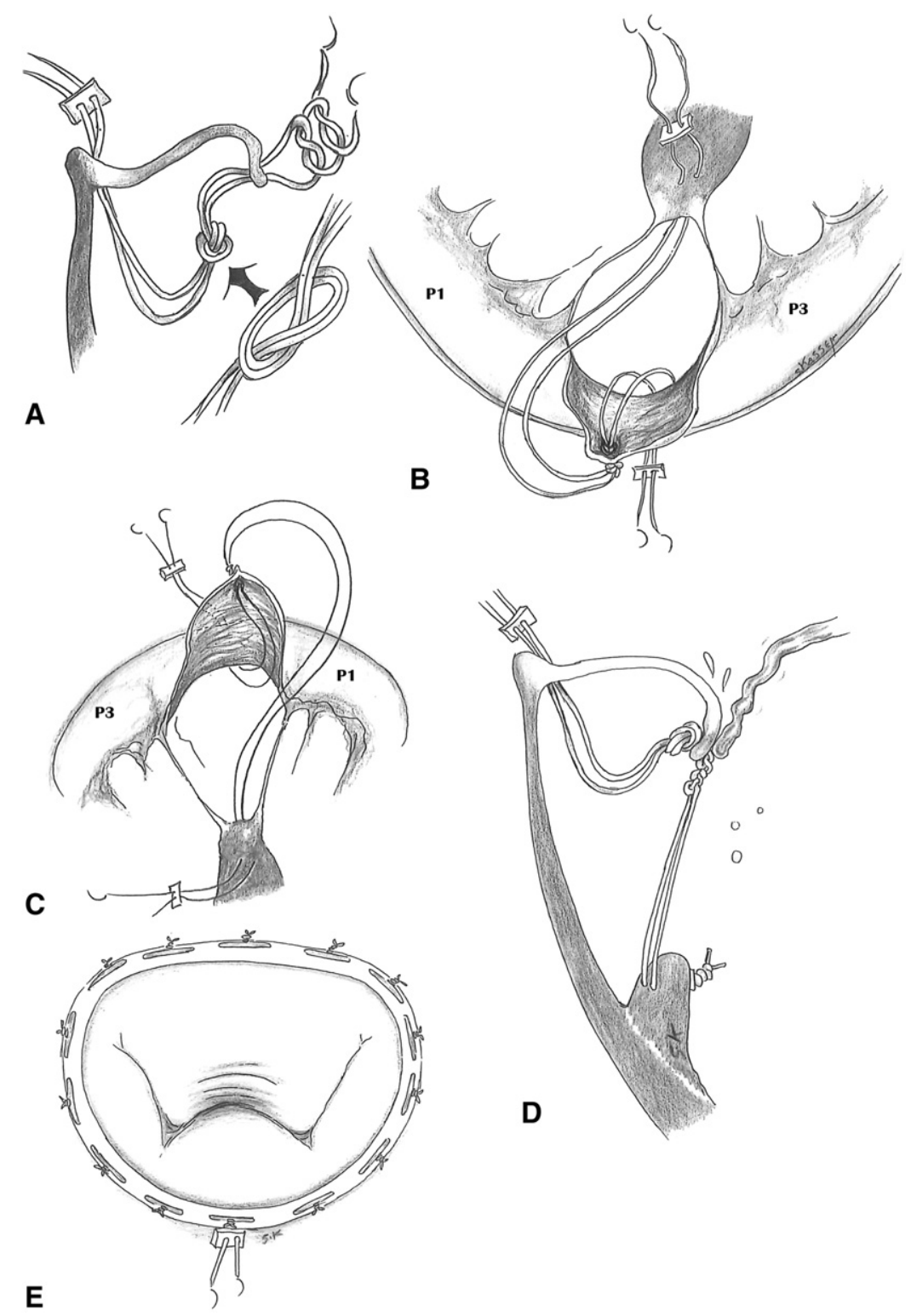

FIGURE 1. A, Pair of 5-0 polytetrafluoroethylene (Gore-Tex; WL Gore \& Associates, Inc, Newark, Del) sutures are passed through the posterior MV annulus from the atrial to the ventricular side at the site corresponding to the tip of the prolapsing P2. A nonsliding knot is tied on the ventricular side. The 2 arms of the sutures are passed through the thickened P2 free edge from the ventricular to the atrial side and tightly knotted to anchor the P2 edge into the new chord. B, The 2 needles are passed through the tip of the papillary muscle with a backhanded technique and then through an expanded polytetrafluoroethylene pledget without tying. Thus, the new chord arises from the papillary side that faces the posterior ventricular wall. C, AEP stitch as seen by the surgeon's assistant. D, Cross-profile shows that the length of the E-P component is determined by saline injection test. E, Slightly oversized ring is inserted into the mitral annulus with interrupted horizontal mattress sutures. The pledget of the untied atrial E-P suture behind the ring is free. Another saline injection test is performed with considerable pressure once the ring is in its definitive position. The valve is continent but anatomically abnormal (sadshape).

\section{DISCUSSION}

Many MV repair strategies have been developed to restore a physiologic PL motion with sufficient line of coaptation, to minimize the transmitral gradients, and to stabilize the mitral annulus. ${ }^{5}$ With the AEP technique, the physiologic and "disciplinary" motion of the PL is conserved. The smooth large surface of P2 and the P1 and P3 rough zones guarantee a long coaptation line and shift the coaptation point away from the left ventricular outflow tract. Furthermore, the AEP stitch provides a supplementary reinforcement for the corresponding left ventricular wall by conserving a dynamic annulo-ventricular continuity. In addition, this technique conserves the annular physiologic geometry and provides the largest orifice area by implanting 

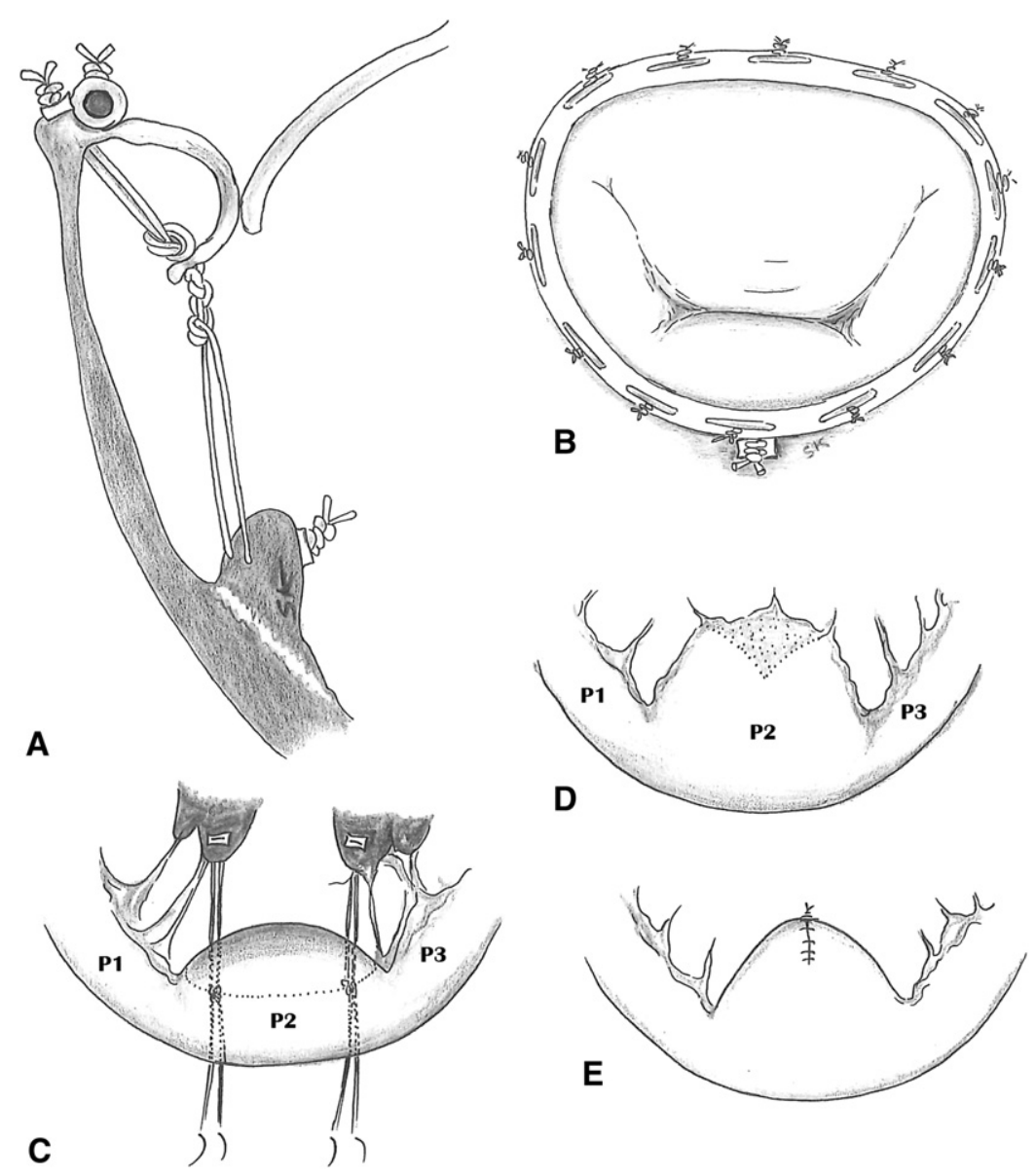

FIGURE 2. A, Cross-profile shows that the height of the $\mathrm{P} 2$ is controlled by the E-A component, so to decrease the height of $\mathrm{P} 2$, it is enough to pull the untied atrial suture behind the ring, giving A2 of the anterior leaflet its space in the radial direction of the valvular area. B, The MV regains its smile-shape before left atriotomy closure. C, Two AEP stitches can be implanted if P2 has a square, rectangle, or trapezoid shape. D, P2 is remodeled by a small triangular-shaped resection. Care should be taken to keep the new smooth surface coaptation of $\mathrm{P} 2$ clear, which is at the same level of rough line coaptation of P1 and P3, and not touch it. E, The 2 free edges are then sewn by a locked running suture of 4-0 Cardionyl (Peters, Paris, France).

an oversized annuloplasty ring. The physiologic valve closure without changing the direction of the nonelongated native chords, which seem to be healthy, minimizes chordal and leaflet tension.

\section{CONCLUSIONS}

This technique can be easily performed with excellent early postoperative results in patients with myxomatous prolapsing P2. Longer-term follow-up and more cases will be required to demonstrate the effectiveness of this nonresection technique.

\section{References}

1. Galloway AC, Colvin SB, Baumann FG, et al. A comparison of mitral valve reconstruction with mitral valve replacement: intermediate-term results. Ann Thorac Surg. 1989;47:655-62.

2. Galloway AC, Colvin SB, Baumann FG, et al. Long-term results of mitral valve reconstruction with Carpentier techniques in 148 patients with mitral insufficiency. Circulation. 1988;78(Suppl 1):I-97-105.

3. Cohn LH, DiSesa VJ, Couper GS, et al. Mitral valve repair for myxomatous degeneration and prolapse of the mitral valve. J Thorac Cardiovasc Surg. 1989;98:987-3.

4. Ranganathan N, Lam JHC, Wigle ED, Silver MD. Morphology of the human mitral valve. II. The valve leaflets. Circulation. 1970;41:459-66.

5. Filsoufi F, Carpentier A. Reconstructive surgery in mitral valve disease. Semin Thorac Cardiovasc Surg. 2007;19:103-10. 